\title{
Role of radio-ablative technique for optimizing the survival of patients with locally advanced pancreatic adenocarcinoma (Review)
}

\author{
IOANA IANCU ${ }^{1,2^{*}}$, ADRIAN BARTOȘ ${ }^{1,3^{*}}$, CRISTIAN LIVIU CIOLTEAN ${ }^{1 *}$, \\ CAIUS BREAZU ${ }^{1,4}$, CORNEL IANCU $^{1}$ and DANA BARTOȘ ${ }^{1,2}$ \\ ${ }^{1}$ Department of Surgery, Regional Institute of Gastroenterology and Hepatology, 400162 Cluj-Napoca; \\ 2 Anatomy and Embryology Department, 'Iuliu Hațieganu' University of Medicine and Pharmacy, 400006 Cluj-Napoca; \\ ${ }^{3}$ Department of Surgery, 'Iuliu Haţieganu' University of Medicine and Pharmacy; \\ ${ }^{4}$ Department of Anesthesiology and Intensive Care, Regional Institute of Gastroenterology and Hepatology, \\ 400162 Cluj-Napoca, Romania
}

Received April 5, 2021; Accepted May 5, 2021

DOI: $10.3892 /$ etm.2021.10285

\begin{abstract}
Pancreatic ductal adenocarcinoma (PDAC) is one of the most common and frequently diagnosed malignant tumor of the pancreas with few treatment options and poor life expectancy. Despite the advances in the surgical field, $40 \%$ of the patients are diagnosed with locally advanced disease which is not suitable for surgery. Radio-frequency ablation (RFA) has been described as a new 'weapon' in the multimodal treatment of PDAC, representing a cytoreductive procedure which must be completed with radiotherapy or chemo-radiotherapy. A systematic research was carried out utilizing the PubMed database in regards to this subject, to evaluate the role of RFA in PDAC management. Abstracts, letters-to-the-editor and non-English language manuscripts were excluded. The literature showed that RFA can be used in open and laparoscopic surgery but it is also feasible for endoscopic ultrasound (EUS-guided RFA) or percutaneous approach. Even though we found optimistic and encouraging reports on overall survival (OS), randomized studies are still required to corroborate these findings. Our review research underline that surgical resection remains the only radical treatment option, RFA being a safe and feasible technique reserved for unresectable, non-metastatic pancreatic tumors.
\end{abstract}

Correspondence to: Dr Adrian Bartoș, Department of Surgery, Regional Institute of Gastroenterology and Hepatology, 19-21 Croitorilor Street, 400162 Cluj-Napoca, Romania

E-mail: bartos.adi@gmail.com

${ }^{*}$ Contributed equally

Key words: pancreatic adenocarcinoma, radio-frequency ablation, locally advanced cancer, non-metastatic pancreatic cancer, palliative treatment
Its combination with oncological treatment can improve the OS of these patients.

\section{Contents}

1. Introduction: Rational for radiofrequency ablation of pancreatic tumors

2. Methods

3. Results

4. Discussion

5. Perspectives

6. Conclusions

1. Introduction: Rational for radiofrequency ablation of pancreatic tumors

To date, pancreatic ductal adenocarcinoma (PDAC) represents the most frequently diagnosed malignant tumor of the pancreas, with the worst prognosis (1). At the time of diagnosis, only $20 \%$ of PDAC cases are resectable due to their aggressive histopathological type and late diagnosis. The overall 5-year survival rate, depending on TNM stage is approximately $7-25 \%(2,3)$. Most of the patients are candidates for chemotherapy or chemoradiotherapy according to various protocols. Despite the advances in the imaging field, $40 \%$ of the patients are diagnosed intraoperatively with locally advanced disease, which is not suitable for radical surgery, even after neoadjuvant treatments (4-6). Median overall survival (OS) for patients who undergo surgery and adjuvant therapy is about 20-22 months. Patients with locally advanced disease (stage III) who are treated with chemoradiotherapy exhibit an OS of approximately 9-13 months, while for patients with stage IV the median survival rate is approximately 2-6 months (7-9).

Locally advanced pancreatic carcinoma (LAPC) is characterized by invasion of the nearby vessels, without the 
possibility of resection or reconstruction, in the absence of systemic disease (distant metastases) (10-12) (Table I).

Borderline resectability refers to the absence of distant metastases, involvement of superior mesenteric vein (SMV) or portal vein (PV), no encasement of nearby arteries, no extension to the celiac axis, encasement of the superior mesenteric artery (SMA) $<180^{\circ}$, local lymph node metastases (13-17) (Table I).

Unresectable LAPC refers to the absence of distant metastases, involvement of SMV or PV, unreconstructable vein occlusion, encasement of celiac artery $>180^{\circ}$, encasement of SMA $>180^{\circ}$, distant lymph node metastases $(13,14,16,18)$ (Table I).

Radio-frequency ablation (RFA) has been described as a new 'weapon' in the multimodal treatment of PDAC, after successful treatment of hepatic, renal, brain and pulmonary tumors (19). RFA is a thermal ablative technique which generates local high temperatures leading to coagulative necrosis, apoptosis and protein denaturation (20-22). The direct effect of RFA is represented by the necrotic area which can be identified immediately after the procedure. At the peripheral cells, RFA may induce an alteration of the metabolic endocellular process that makes them sensitive to further treatments such as chemotherapy or chemoradiotherapy $(20,23)$. In addition, RFA induces antitumor antibodies due to activation of proinflammatory cytokines, T, B and natural killer (NK) lymphocytes (23).

Surgical resection is the only radical treatment for resectable pancreatic cancer; RFA being indicated for unresectable, non-metastatic, locally advanced pancreatic tumors (24) (Table II). The presence of metastases is an exclusion criterion due to the fact that the disease exhibits systemic spread (25).

RFA induce focal hyperthermic injury to ablated cells, which affects the tumor microenvironment and damages cells at the membrane and subcellular levels. Mechanical cell damage that is generated by heat-induced necrosis releases various immunogenic intracellular substrates which lead to the activation of the immune system (26). Pro-inflammatory cytokines are released from the ablated tissue. Levels of serum interleukin-1 $\beta$ (IL-1 $\beta$ ), IL-6, IL-8 and tumor necrosis factor- $\alpha$ (TNF $\alpha)$ have all been shown to be increased after RFA. Increasing the level of cytokines by RFA has been shown to have a key role in stimulating the antitumor immune response-'vaccine antitumoral' (26). Increased levels of tumor-specific $\mathrm{T}$ cells have been detected in post-RFA cancer patients and confer increased tumor-free survival in certain patients. There is information from the literature which indicate that RFA performed in a neoadjuvant setting could offer clinical benefits that might be superior to conventional neoadjuvant treatments (27). RFA performed as a neoadjuvant treatment can decrease the size of the tumor and increase the possibility of obtaining negative margins at the time of surgery (27). The main purpose for neoadjuvant treatment is to obtain downstaging but this only occurs in 15 to $30 \%$ of cases with chemotherapy followed by radiotherapy (3). There are some studies which show that RFA associated with chemoradiotherapy seems to have an important role in downstaging and could lead to radical surgery $(3,5,28)$.

Regarding the value of the CA19-9 tumoral marker, it has been shown that the RFA of pancreatic tumors leads to reduction in the CA19-9 level. One previous study considered that the larger is the ablated area, the more important is the CA19-9 level reduction (29).

Local ablation techniques appear to be a future therapeutic option for patients with stage III pancreatic adenocarcinoma. RFA and irreversible electroporation (IRE) are actually the latest local ablation techniques used for patients with LAPC. Initial clinical trials on the use of these techniques have already shown encouraging results in terms of safety and feasibility $(3,22)$.

To date, the indications for RFA of pancreatic tumors are: Stage III PDAC (3); patients no longer responding to standard system therapy, for local control and immune additive response; patients with stage IV pancreatic adenocarcinoma (with metastatic disease-only some studies, for local control of the disease) $(30,31)$ (Table II).

According to recent studies, the ideal parameters for RFA are actually represented by $90^{\circ}$ for $5 \mathrm{~min}$, with a distance of $10 \mathrm{~mm}$ between the probe and the duodenum and portomesenteric axis (3). In addition, according to the proximity of the tumor with the vital surrounding structure, the ablation of the entire tumor is contraindicated: A peripheral 'security ring' of tissue is left in place, to avoid thermal injuries of the nearby structures. This 'security ring' can be later targeted by the use of chemo/radiotherapy $(3,22)$.

According the proximity of the tumor to vital structures such as the upper mesenteric artery, upper mesenteric vein, duodenum, tumor ablation may be incomplete. Furthermore, tumoral tissue that cannot be subjected to RFA therapy is subject to radiotherapy (32).

The surgical approach to RFA for pancreatic tumors is performed under general anesthesia and involves access to the abdominal cavity by laparotomy (medial or bi-subcostal incision). The next step refers to the inspection of the peritoneal cavity, liver surface palpation for the detection of eventual metastases and liver/pancreas intra-operative ultrasound (31). Surgery continues with the Kocher maneuver. The pancreatic head must be fully mobilized from the inferior vena cava to the level where the left renal vein intersects the aorta, so the pancreatic head and the uncinate process may be throbbed between the left hand fingers. The purpose of this maneuver is to appreciate the relationship of the pancreatic head to the large vessels (eventual invasion). The entry into the omental bursa is performed by cutting the gastro-colic ligament. The pancreatic tumor is biopsied if there is no preoperative examination to confirm malignancy (extemporaneous exam). For ablation time, a RITA device is used as a (AngioDynamics) generator (33). The ablation needle is inserted into the tumor under the ultrasound guidance (33). The number of ablations must be done according to the size of the tumor and the relationships with the adjacent structures. The duration of the sessions will be $5 \mathrm{~min}$ and an ablation temperature of $90^{\circ}$; the distance between the ablation needle, the duodenum and the portomesenteric axis will be at least $10 \mathrm{~mm}$ (3). During ablation, a naso-gastric catheter will be mounted and cold saline solution will be administered to prevent thermal injury to the stomach or duodenum $(32,34)$. Drains are placed at the level of the omental bursa and Douglas space.

Even if the temperature of the ablation technique has been validated to be safe at $90^{\circ}$, there are no general agreements on the most appropriate RFA parameters and standardization 
of the operative technique. Fegrachi et al recommended in a porcine experiment that the needle used for the RFA procedure must be at least $10 \mathrm{~mm}$ from the first part of the small bowel (duodenum) and portomesenteric vessels (35-37). It is also recommended that cold saline solutions must be administered through the naso-gastric tube to prevent the thermal injury of the duodenum $\left(100 \mathrm{ml} / \mathrm{min}\right.$ saline at $\left.5^{\circ}\right)(35-37)$. By reducing the temperature, they registered lower complication rates. The temperature between $60^{\circ}$ and $100^{\circ}$ induced immediate coagulation of the tissue with irreversible damage to the inner structure of the cells, while using $100^{\circ}-110^{\circ}$ induced tissue vaporization and carbonization (35-37).

The ablation procedure is in most of the cases associated with palliative surgery such as biliary or digestive bypass or both of them. Siriwardena recommended that no patients should undergo surgery only for ablation (21).

\section{Methods}

A systematic research was carried out in PubMed using the keywords 'radio-frequency ablation' or 'RFA' of 'pancreatic tumors' for papers published in English up to April 2019. All papers identified in our first search were reviewed to indicate those studies that were carried out on patients with unresectable pancreatic tumors undergoing ablation. We identified a number of 11 articles. Case reports were also included (Table III).

The primary endpoint was to investigate the safety and complications of these techniques, while the secondary endpoint included patient survival and quality of life in terms of the control of symptoms.

\section{Results}

In the present review, we analyzed 11 studies: 2 case reports, 5 retrospective studies and 4 prospective papers.

Complications which were reported to occur were related to the associated surgery or to the RFA procedure. RFA-related complications included: Severe acute pancreatitis, pancreatic fistula, duodenal perforation, and vascular damage (PV thrombosis, hemorrhage) (Table III). Complications related to palliative surgery referred to postoperative bleeding, biliary fistulas, digestive fistulas, and abdominal fluid collection. Adjustment of the RFA temperature (reducing from $105^{\circ}$ to $90^{\circ}$ ) was found to lead to a significant decrease in postoperative complications. Girelli et al reported in a recent study of 100 cases using RFA of the pancreas that the overall morbidity was approximately $26 \%$ with a $24 \%$ incidence of abdominal complications, but not all related to the RFA (Table III) (3). The first 25 patients had a complication rate of $40 \%$ due to the high temperature used $\left(105^{\circ}\right)$, while the rest of the patients had a reduced complication rate due to the adjustment of the temperature (3). Girelli et al reported an OS at 1 year of $41 \%$ (3). Date et al reported in a porcine model that reducing the temperature from $105^{\circ}$ to $90^{\circ}$ and an ablation time of 5 min was safer and no mesenteric or portal thrombosis was recorded (38). Concerning the same idea, Girelli et al reported that when using the right temperature, the mortality rate was about $2 \%$ (22), while Wu et al reported that the mortality rate could rise to $25 \%$ due to postoperative bleeding (34). Wu et al 
Table II. Indications for RFA of pancreatic tumors.

Main indications

Relative indications

Stage III ductal adenocarcinoma without distant metastasis-pancreatic head

Stage III ductal adenocarcinoma without distant metastasis-pancreatic body and tail
Patients no longer responding to standard system therapy

Patients with stage IV pancreatic adenocarcinoma-patients with metastatic disease (only some studies, for local control of the disease)

Borderline tumors, before neoadjuvant treatment

RFA, radio-frequency ablation.

also reported a morbidity of $18.8 \%$ (34). Girelli et al reported a morbidity of $28 \%$, while the mortality rate was $1.8 \%$ (3). From the literature reports we observed an OS of 14.7 months for patients which undergo only RFA, while the patients who benefit from RFA and them chemoradiotherapy have an OS of 25.6 months $(3,6,33)$. Matsui et al considered that the method is relatively safe and is feasible to treat unresectable tumors without metastasis; the authors showed that the mortality rate was about $10 \%$ and the OS median was 3 months (Table III) (30).

In contast, Spiliotis et al reported their experience with zero mortality and an OS of 33 months (31). In addition, Frigerio et al reported in his paper $0 \%$ mortality and a median OS of 19 months (33).

Date and Siriwardena reported one case of unresectable pancreatic adenocarcinoma which was suitable for radiofrequency ablation with a survival of only 3 months after the procedure (39). Furthermore, Hadjicostas et al reported no complication after the procedure, but all of the patients died at 3 months after the procedure (40). In addition, Casadei et al reported that all of the patients developed complications after the procedure and the OS at 5 months was $0 \%$ (41). Figueroa-Barojas et al studied 20 patients and reported a median OS of 19 months (42). Varshney et al reported in their study 3 patients who were suitable for pancreatic ablation; one patient died at 1 month (Table III) (43).

\section{Discussion}

RFA of pancreatic tumors is not a radical procedure, being a cytoreductive treatment which must be completed with radiotherapy or chemo-radiotherapy.

As described above, RFA of the pancreas is a technique which can improve the survival of patients with unresectable LAPC. There are still discussions related to the role of neoadjuvant treatment for LAPC. Using systemic chemotherapy as an up-front treatment has been thought to benefit the survival rate due to the early dissemination risk of pancreatic carcinoma. For the chemotherapy of pancreatic carcinoma, gemcitabine and FOLFIRINOX combination have been used. Gemcitabine offers an OS of 9.2-11.7 months while patients who undergo FOLFIRINOX chemotherapy have an OS of 11.7 months (44). FOLFIRINOX treatment includes administration of leucovorin, 5-fluorouracil, irinotecan and oxaliplatin $(45,46)$. Giardino et al reports a median OS of 25.6 months for patients who benefit from neoadjuvant treatment and RFA while patients who undergo RFA plus radiochemotherapy and intra-arterial chemotherapy have a median OS of about 34 months (24). From a report made by Fegrachi et al, we found a median survival of 25.6 months for these patients (36), while Matsui et al reported a median survival of only 5 months (30). For other authors, patients with advanced pancreatic carcinoma who benefit from RFA as an up-front treatment and then adjuvant chemotherapy have a poorer OS (24). On the other hand, there are some papers which report that using RFA as an up-front treatment could lead to the modulation of the immune system $(20,27,47)$.

While the direct effect of RFA is clearly represented by the necrotic area immediately identifiable after the procedure, on the other hand, the indirect effects are on the viable zone adjacent to this area (transition or peripheral zone). The cells populating the peripheral zone are affected by RFA in terms of the alteration of metabolic endocellular processes that makes them quite sensitive to further cytolytic therapies, such as chemotherapy or chemoradiotherapy.

Even if an article written by Fegrachi et al states that the survival rate is 25.6 months for patients who undergo chemotherapy followed by RFA, there are some results which underlines that the rate of early progression (12.3 and $16 \%$ ) and the survival rate (19 months) are the same with or without chemotherapy before the procedure $(33,36)$. An increasing number of studies have been published regarding the role of thermal ablation for stimulating and modulating the immune system and the immune response against the tumor. Dromi et al demonstrated using laboratory animals an increase in the infiltration of dendritic cells, which are the most powerful antigen-presenting cells, following the ablation; subtotal RFA treatment results in systemic antitumor $\mathrm{T}$ cell immune responses and tumor regression (23).

Over the last decades, new approaches of using RFA for pancreatic tumors have been cited (48). RFA can be used in open surgery, laparoscopic surgery but also by endoscopic (EUS-guided RFA) (48) or percutaneous approach $(49,50)$. There are previous studies which have shown that RFA is a safe and feasible technique for patients with unresectable pancreatic cancer, no matter the approach $(51,52)$. Open approach is the most commonly used technique due to the anatomical location of the pancreas $(53,54)$. By this approach, the main advantage is that the surgeon can be very accurate with the RFA technique, by exposing the anatomical landmarks. In the same idea, the intraoperative incidents (hemorrhage) can be easily controlled. The laparoscopic approach is a good alternative, 


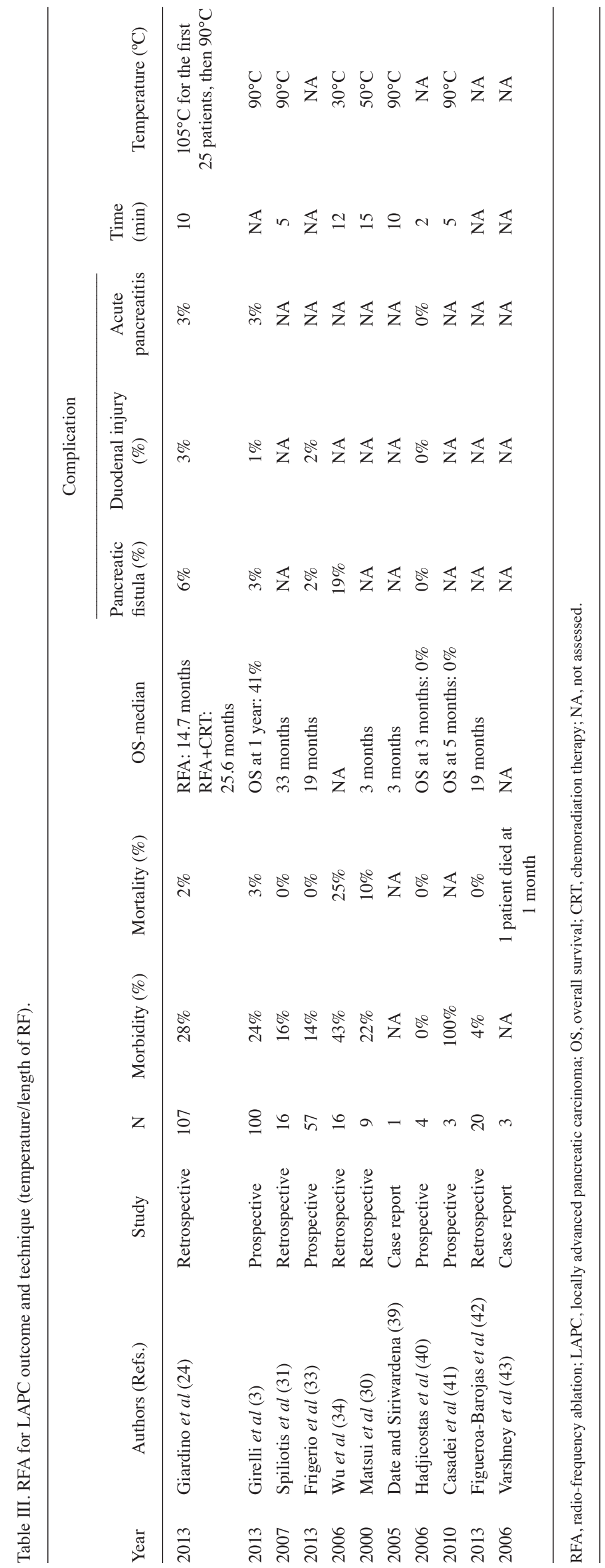


with the advantages of minimally invasive approach, together with the safety of surgical maneuvers.

EUS-guided RFA. EUS-guided RFA is a minimally invasive technique, with a success rate of $100 \%$ in human studies, being a good alternative to surgery $(55,56)$. The pancreas can be accessed endoscopically via transgastric or transduodenal approach $(48,57)$. In a paper by Pai et al we found that they reported that the technique is safe and well tolerated by patients and also has an important role in decreasing the tumor size and CA19-9 levels (58). Pai et al described abdominal pain in 25 to $33 \%$ of the patients, but with no major complication reported in human studies (58).

Percutaneous RFA. Percutaneous RFA is limited by the anatomical topography, quality of imaging guidance and access to the tumor. This is a minimally invasive technique which permits the treatment of patients with important comorbidities and with contraindication for general anesthesia $(50,59)$. There are some recent studies which report no deaths related to this procedure (51). Regarding complications, Rossi et al described diffuse abdominal pain, pancreatitis associated with thermal injury and peripancreatic collection, but no major complications (53). Rossi et al sustained that only doctors with substantial experience in interventional US-guided procedures must perform the percutaneous approach due to the proximity of the pancreas with the celiac trunk, superior mesenteric vein, PV and duodenum (53). Carrafiello et al reported that this is a safe and feasible technique for tumors located in the body-tail of the pancreas $(49,60)$.

\section{Perspectives}

In addition to RFA, there are new techniques which have been developed to optimize the management of locally advanced pancreatic tumors: Microwave ablation, cryoablation, high intensity focused ultrasound (HIFU) and IRE.

Microwave ablation. Microwave ablation is a technique which induces tissue heating in the area of interest. The main difference between microwave ablation and RFA refers to the frequency range of the electromagnetic waves which leads to a better ablation volume. This procedure is associated with fewer complications than RFA and it takes a shorter operative time $(49,54)$.

Cryoablation. Cryoablation is a procedure which freezes tumoral tissue leading to necrosis of the tumor. Complication rates range from 0 to $40 \%$, the most important being severe bleeding and pancreatitis. The mortality rate of this procedure is low. Li et al reported that cryoablation of pancreatic tumors associated with bypass surgery can improve the quality of life in these patients (61).

High intensity focused ultrasound (HIFU). High intensity focused ultrasound (HIFU) leads to thermal tissue damage due to the boiling bubbles which disrupt the tissue mechanically. This technique needs to be guided by high resolution imaging techniques such as MRI. It is a safe, effective and feasible technique for patients with LAPC. The median survival of patients which benefits from HIFU ranges from 10 to 12.6 months according to some studies. Also, there are no complications reported (62-65).

IRE. IRE is a non-thermal ablation procedure which was developed in the last few years for the treatment of LAPC. This procedure induces cell death due to the delivery of short high-voltage electric current fields. Complications are reported in about $13 \%$ of patients, while the IRE-related mortality is $2 \%$. The main complications appear to be duodenal perforation, bile leakage and pancreatic fistula (66). Martin et al reported in a study that IRE prolonged OS by 9 months (67).

\section{Conclusions}

Although surgical resection remains the only radical treatment for LAPC, palliative management has been improved in the last few decades. RFA is a safe and feasible technique which can be performed by open, laparoscopic, endoscopic or by percutaneous approach and can be associated with low complications rates if a standardized technique is used. Most important is that in combination with chemotherapy and chemoradiotherapy, RFA leads to prolonged OS of LAPC patients. However, RFA together with the new ablative procedures mentioned above must be re-evaluated by a prospective multicentric approach and a protocol of selection and conduit must be standardized.

\section{Acknowledgements}

Not applicable.

\section{Funding}

No funding was received.

\section{Availability of data and materials}

All data generated or analyzed during this study are included in this published article.

\section{Authors' contributions}

II, $\mathrm{AB}$, and $\mathrm{DB}$ designed and performed the review. II, AB and CLC wrote the paper. CI and CB reviewed the literature and revised the manuscript accordingly. All authors read and approved the final manuscript.

\section{Ethics approval and consent to participate}

Not applicable.

\section{Patient consent for publication}

Not applicable.

\section{Competing interests}

The authors declared no potential competing interests with respect to the research, authorship, and/or publication of this article. 


\section{References}

1. Schima W, Ba-Ssalamah A, Kölblinger C, Kulinna-Cosentini C, Puespoek A and Götzinger P: Pancreatic adenocarcinoma. Eur Radiol 17: 638-649, 2007.

2. Neoptolemos JP, Dunn JA, Stocken DD, Almond J, Link K Beger H, Bassi C, Falconi M, Pederzoli P, Dervenis C, et al: Adjuvant chemoradiotherapy and chemotherapy in resectable pancreatic cancer: A randomised controlled trial. Lancet 358: $1576-1585,2001$

3. Girelli R, Frigerio I, Giardino A, Regi P, Gobbo S, Malleo G, Salvia R and Bassi C: Results of 100 pancreatic radiofrequency ablations in the context of a multimodal strategy for stage III ductal adenocarcinoma. Langenbecks Arch Surg 398: 63-69, 2013.

4. Singh SM, Longmire WP Jr and Reber HA: Surgical palliation for pancreatic cancer. The UCLA experience. Ann Surg 212: $132-139,1990$

5. Huguet F, Girard N, Guerche CS, Hennequin C, Mornex F and Azria D: Chemoradiotherapy in the management of locally advanced pancreatic carcinoma: A qualitative systematic review. J Clin Oncol 27: 2269-2277, 2009.

6. Paiella S, Salvia R, Ramera M, Girelli R, Frigerio I, Giardino A, Allegrini V and Bassi C: Local ablative strategies for ductal pancreatic cancer (radiofrequency ablation, irreversible electroporation): A review. Gastroenterol Res Pract 2016: 4508376 , 2016.

7. Rocha Lima CM, Green MR, Rotche R, Miller WH Jr, Jeffrey GM, Cisar LA, Morganti A, Orlando N, Gruia G and Miller LL: Irinotecan plus gemcitabine results in no survival advantage compared with gemcitabine monotherapy in patients with locally advanced or metastatic pancreatic cancer despite increased tumor response rate. J Clin Oncol 22: 3776-3783, 2004

8. Louvet C, Labianca R, Hammel P, Lledo G, Zampino MG, André T, Zaniboni A, Ducreux M, Aitini E, Taïeb J, et al: Gemcitabine in combination with oxaliplatin compared with gemcitabine alone in locally advanced or metastatic pancreatic cancer: Results of a GERCOR and GISCAD phase III trial. J Clin Oncol 23: 3509-3516, 2005.

9. Poplin E, Feng Y, Berlin J, Rothenberg ML, Hochster H, Mitchell E, Alberts S, O'Dwyer P, Haller D, Catalano P, et al: Phase III, randomized study of gemcitabine and oxaliplatin versus gemcitabine (fixed-dose rate infusion) compared with gemcitabine (30-min infusion) in patients with pancreatic carcinoma E6201: A trial of the Eastern cooperative oncology group. J Clin Oncol 27: 3778-3785, 2009.

10. Hidalgo M: Pancreatic cancer. N Engl J Med 362: 1605-1617, 2010.

11. Heinemann V, Haas M and Boeck S: Neoadjuvant treatment of borderline resectable and non-resectable pancreatic cancer. Ann Oncol 24: 2484-2492, 2013.

12. He J, Page AJ, Weiss M, Wolfgang CL, Herman JM and Pawlik TM: Management of borderline and locally advanced pancreatic cancer: Where do we stand? World J Gastroenterol 20: 2255-2266, 2014

13. Vauthey JN and Dixon E: AHPBA/SSO/SSAT consensus conference on resectable and borderline resectable pancreatic cancer: Rationale and overview of the conference. Ann Surg Oncol 16: $1725-1726,2009$.

14. Halperin DM and Varadhachary GR: Resectable, borderline resectable, and locally advanced pancreatic cancer: What does it matter? Curr Oncol Rep 16: 366, 2014.

15. Katz $\mathrm{MH}, \mathrm{Crane} \mathrm{CH}$ and Varadhachary G: Management of borderline resectable pancreatic cancer. Semin Radiat Oncol 24 105-112, 2014

16. Benson AB III, D'Angelica MI, Abbott DE, Abrams TA, Alberts SR, Saenz DA, Are C, Brown DB, Chang DT, Covey AM, et al: NCCN guidelines insights: Hepatobiliary cancers, version 1.2017. J Natl Compr Canc Netw 15: 563-573, 2017.

17. Katz MHG and Varadhachary GR: Borderline resectable pancreatic cancer-at the crossroads of precision medicine. Cancer 125 : $1584-1587,2019$

18. Varadhachary GR: Preoperative therapies for resectable and borderline resectable pancreatic cancer. J Gastrointest Oncol 2: $136-142,2011$

19. Gazelle GS, Goldberg SN, Solbiati L and Livraghi T: Tumor ablation with radio-frequency energy. Radiology 217: 633-646, 2000.
20. Rovere-Querini P and Manfredi AA: Tumor destruction and in situ delivery of antigen presenting cells promote anti-neoplastic immune responses: Implications for the immunotherapy of pancreatic cancer. JOP 5: 308-314, 2004.

21. Siriwardena AK: Radiofrequency ablation for locally advanced cancer of the pancreas. JOP 7: 1-4, 2006.

22. Girelli R, Frigerio I, Salvia R, Barbi E, Tinazzi Martini P and Bassi C: Feasibility and safety of radiofrequency ablation for locally advanced pancreatic cancer. Br J Surg 97: 220-225, 2010.

23. Dromi SA, Walsh MP, Herby S, Traughber B, Xie J, Sharma KV, Sekhar KP, Luk A, Liewehr DJ, Dreher MR, et al: Radiofrequency ablation induces antigen-presenting cell infiltration and amplification of weak tumor-induced immunity. Radiology 251: 58-66, 2009.

24. Giardino A, Girelli R, Frigerio I, Regi P, Cantore M, Alessandra A, Lusenti A, Salvia R, Bassi C and Pederzoli P: Triple approach strategy for patients with locally advanced pancreatic carcinoma. HPB (Oxford) 15: 623-627, 2013.

25. Shrestha B, Sun Y, Faisal F, Kim V, Soares K, Blair A, Herman JM, Narang A, Dholakia AS, Rosati L, et al: Long-term survival benefit of upfront chemotherapy in patients with newly diagnosed borderline resectable pancreatic cancer. Cancer Med 6: 1552-1562, 2017

26. Chu KF and Dupuy DE: Thermal ablation of tumours: Biological mechanisms and advances in therapy. Nat Rev Cancer 14: 199-208, 2014

27. Hansler J, Wissniowski TT, Schuppan D, Witte A, Bernatik T, Hahn EG and Strobel D: Activation and dramatically increased cytolytic activity of tumor specific $\mathrm{T}$ lymphocytes after radio-frequency ablation in patients with hepatocellular carcinoma and colorectal liver metastases. World J Gastroenterol 12: 3716-3721, 2006.

28. Morganti AG, Massaccesi M,La Torre G, Caravatta L, Piscopo A, Tambaro R, Sofo L, Sallustio G, Ingrosso M, Macchia G, et al: A systematic review of resectability and survival after concurrent chemoradiation in primarily unresectable pancreatic cancer. Ann Surg Oncol 17: 194-205, 2010.

29. D'Onofrio M, Barbi E, Girelli R, Tinazzi Martini P, De Robertis R, Ciaravino V, Salvia R, Butturini G, Frigerio I, Milazzo T, et al: Variation of tumoral marker after radiofrequency ablation of pancreatic adenocarcinoma. J Gastrointest Oncol 7: 213-220, 2016

30. Matsui Y, Nakagawa A, Kamiyama Y, Yamamoto K, Kubo N and Nakase Y: Selective thermocoagulation of unresectable pancreatic cancers by using radiofrequency capacitive heating. Pancreas 20: 14-20, 2000.

31. Spiliotis JD, Datsis AC, Michalopoulos NV, Kekelos SP Vaxevanidou A, Rogdakis AG and Christopoulou AN: Radiofrequency ablation combined with palliative surgery may prolong survival of patients with advanced cancer of the pancreas. Langenbecks Arch Surg 392: 55-60, 2007.

32. Spiliotis JD, Datsis AC, Michalopoulos NV, Kekelos SP Vaxevanidou A, Rogdakis AG and Christopoulou AN: High operative risk of cool-tip radiofrequency ablation for unresectable pancreatic head cancer. J Surg Oncol 96: 89-90, 2007.

33. Frigerio I, Girelli R, Giardino A, Regi P, Salvia R and Bassi C: Short term chemotherapy followed by radiofrequency ablation in stage III pancreatic cancer: Results from a single center. J Hepatobiliary Pancreat Sci 20: 574-577, 2013.

34. Wu Y, Tang Z, Fang H, Gao S, Chen J, Wang Y and Yan H: High operative risk of cool-tip radiofrequency ablation for unresectable pancreatic head cancer. J Surg Oncol 94: 392-395, 2006.

35. Fegrachi S, Molenaar IQ, Klaessens JH, Besselink MG, Offerhaus JA and van Hillegersberg R: Radiofrequency ablation of the pancreas with and without intraluminal duodenal cooling in a porcine model. J Surg Res 184: 867-872, 2013

36. Fegrachi S, Besselink MG, van Santvoort HC, van Hillegersberg R and Molenaar IQ: Radiofrequency ablation for unresectable locally advanced pancreatic cancer: A systematic review. HPB (Oxford) 16: 119-123, 2014

37. Fegrachi S, Molenaar IQ, Klaessens JH, Besselink MG, Offerhaus JA and van Hillegersberg R: Radiofrequency ablation of the pancreas: Two-week follow-up in a porcine model. Eur J Surg Oncol 40: 1000-1007, 2014.

38. Date RS, Biggins J, Paterson I, Denton J, McMahon RF and Siriwardena AK: Development and validation of an experimental model for the assessment of radiofrequency ablation of pancreatic parenchyma. Pancreas 30: 266-271, 2005.

39. Date RS and Siriwardena AK: Radiofrequency ablation of the pancreas. II: Intra-operative ablation of non-resectable pancreatic cancer. A description of technique and initial outcome. JOP 6: 588-592, 2005. 
40. Hadjicostas P, Malakounides N, Varianos C, Kitiris E, Lerni F and Symeonides P: Radiofrequency ablation in pancreatic cancer. HPB (Oxford) 8: 61-64, 2006.

41. Casadei R, Ricci C, Pezzilli R, Serra C, Calculli L, Morselli-Labate AM, Santini D and Minni F: A prospective study on radiofrequency ablation locally advanced pancreatic cancer. Hepatobiliary Pancreat Dis Int 9: 306-311, 2010.

42. Figueroa-Barojas P, Bakhru MR, Habib NA, Ellen K, Millman J, Jamal-Kabani A, Gaidhane M and Kahaleh M: Safety and efficacy of radiofrequency ablation in the management of unresectable bile duct and pancreatic cancer: A novel palliation technique. J Oncol 2013: 910897, 2013.

43. Varshney S, Sewkani A, Sharma S, Kapoor S, Naik S, Sharma A and Patel K: Radiofrequency ablation of unresectable pancreatic carcinoma: Feasibility, efficacy and safety. JOP 7: 74-78, 2006.

44. Rombouts SJ, Vogel JA, van Santvoort HC, van Lienden KP, van Hillegersberg R, Busch OR, Besselink MG and Molenaar IQ: Systematic review of innovative ablative therapies for the treatment of locally advanced pancreatic cancer. Br J Surg 102: 182-193, 2015

45. Gemenetzis G, Groot VP, Blair AB, Laheru DA, Zheng L, Narang AK, Fishman EK, Hruban RH, Yu J, Burkhart RA, et al: Survival in locally advanced pancreatic cancer after neoadjuvant therapy and surgical resection. Ann Surg 270: 340-347, 2019

46. He J, Blair AB, Groot VP, Javed AA, Burkhart RA, Gemenetzis G, Hruban RH, Waters KM, Poling J, Zheng L, et al: Is a pathological complete response following neoadjuvant chemoradiation associated with prolonged survival in patients with pancreatic cancer? Ann Surg 268: 1-8, 2018.

47. Alistar A, Morris BB, Desnoyer R, Klepin HD, Hosseinzadeh K, Clark C, Cameron A, Leyendecker J, D'Agostino R Jr, Topaloglu U, et al: Safety and tolerability of the first-in-class agent CPI-613 in combination with modified FOLFIRINOX in patients with metastatic pancreatic cancer: A single-centre, open-label, dose-escalation, phase 1 trial. Lancet Oncol 18: 770-778, 2017.

48. Song TJ, Seo DW, Lakhtakia S, Reddy N, Oh DW, Park DH, Lee SS, Lee SK and Kim MH: Initial experience of EUS-guided radiofrequency ablation of unresectable pancreatic cancer. Gastrointest Endosc 83: 440-443, 2016

49. Carrafiello G, Ierardi AM, Fontana F, Petrillo M, Floridi C, Lucchina N, Cuffari S, Dionigi G, Rotondo A and Fugazzola C: Microwave ablation of pancreatic head cancer: Safety and efficacy. J Vasc Interv Radiol 24: 1513-1520, 2013.

50. D'Onofrio M, Crosara S, De Robertis R, Butturini G, Salvia R, Paiella S, Bassi C and Mucelli RP: Percutaneous radiofrequency ablation of unresectable locally advanced pancreatic cancer: Preliminary results. Technol Cancer Res Treat 16: 285-294, 2017

51. Niu L, He L, Zhou L, Mu F, Wu B, Li H, Yang Z, Zuo J and $\mathrm{Xu} \mathrm{K}$ : Percutaneous ultrasonography and computed tomography guided pancreatic cryoablation: Feasibility and safety assessment. Cryobiology 65: 301-307, 2012.

52. Ierardi AM, Biondetti P, Coppola A, Fumarola EM, Biasina AM, Alessio Angileri S and Carrafiello G: Percutaneous microwave thermosphere ablation of pancreatic tumours. Gland Surg 7: 59-66, 2018.

53. Rossi S, Viera FT, Ghittoni G, Cobianchi L, Rosa LL, Siciliani L, Bortolotto C, Veronese L, Vercelli A, Gallotti A and Ravetta V: Radiofrequency ablation of pancreatic neuroendocrine tumors: A pilot study of feasibility, efficacy, and safety. Pancreas 43: 938-945, 2014
54. Vogl TJ, Panahi B, Albrecht MH, Naguib NNN, Nour-Eldin NA, Gruber-Rouh T, Thompson ZM and Basten LM: Microwave ablation of pancreatic tumors. Minim Invasive Ther Allied Technol 27: 33-40, 2018.

55. D'Onofrio M, Zamboni G, Faccioli N, Capelli $\mathrm{P}$ and Pozzi Mucelli R: Ultrasonography of the pancreas. 4. Contrast-enhanced imaging. Abdom Imaging 32: 171-181, 2007.

56. Crinò SF, D'Onofrio M, Bernardoni L, Frulloni L, Iannelli M, Malleo G, Paiella S, Larghi A and Gabbrielli A: EUS-guided radiofrequency ablation (EUS-RFA) of solid pancreatic neoplasm using an 18-gauge needle electrode: Feasibility, safety, and technical success. J Gastrointestin Liver Dis 27: 67-72, 2018.

57. Keane MG, Bramis K, Pereira SP and Fusai GK: Systematic review of novel ablative methods in locally advanced pancreatic cancer. World J Gastroenterol 20: 2267-2278, 2014.

58. Pai M, Habib N, Senturk H, Lakhtakia S, Reddy N, Cicinnati VR, Kaba I, Beckebaum S, Drymousis P, Kahaleh M and Brugge W: Endoscopic ultrasound guided radiofrequency ablation, for pancreatic cystic neoplasms and neuroendocrine tumors. World J Gastrointest Surg 7: 52-59, 2015.

59. Paiella S, De Pastena M, D'Onofrio M, Crinò SF, Pan TL, De Robertis R, Elio G, Martone E, Bassi C and Salvia R: Palliative therapy in pancreatic cancer-interventional treatment with radiofrequency ablation/irreversible electroporation. Transl Gastroenterol Hepatol 3: 80, 2018

60. Carrafiello G, Ierardi AM, Piacentino F, Lucchina N, Dionigi G, Cuffari S and Fugazzola C: Microwave ablation with percutaneous approach for the treatment of pancreatic adenocarcinoma. Cardiovasc Intervent Radiol 35: 439-442, 2012.

61. Li J, Chen X, Yang H, Wang X, Yuan D, Zeng Y, Wen T, Yan L and Li B: Tumour cryoablation combined with palliative bypass surgery in the treatment of unresectable pancreatic cancer: A retrospective study of 142 patients. Postgrad Med J 87: 89-95, 2011.

62. Xiong LL, Hwang JH, Huang XB, Yao SS, He CJ, Ge XH, Ge HY and Wang XF: Early clinical experience using high intensity focused ultrasound for palliation of inoperable pancreatic cancer. JOP 10: 123-129, 2009.

63. Xiaoping L and Leizhen Z: Advances of high intensity focused ultrasound (HIFU) for pancreatic cancer. Int J Hyperthermia 29: 678-682, 2013

64. Diana M, Schiraldi L, Liu YY, Memeo R, Mutter D, Pessaux P and Marescaux J: High intensity focused ultrasound (HIFU) applied to hepato-bilio-pancreatic and the digestive system-current state of the art and future perspectives. Hepatobiliary Surg Nutr 5: 329-344, 2016.

65. Ning Z, Xie J, Chen Q, Zhang C, Xu L, Song L and Meng Z: HIFU is safe, effective, and feasible in pancreatic cancer patients: A monocentric retrospective study among 523 patients. Onco Targets Ther 12: 1021-1029, 2019.

66. Martin RC: Irreversible electroporation of locally advanced pancreatic head adenocarcinoma. J Gastrointest Surg 17: 1850-1856, 2013

67. Martin RC II, McFarland K, Ellis S and Velanovich V: Irreversible electroporation in locally advanced pancreatic cancer: Potential improved overall survival. Ann Surg Oncol 20 (Suppl 3): S443-S449, 2013.

This work is licensed under a Creative Commons Attribution-NonCommercial-NoDerivatives 4.0 International (CC BY-NC-ND 4.0) License. 